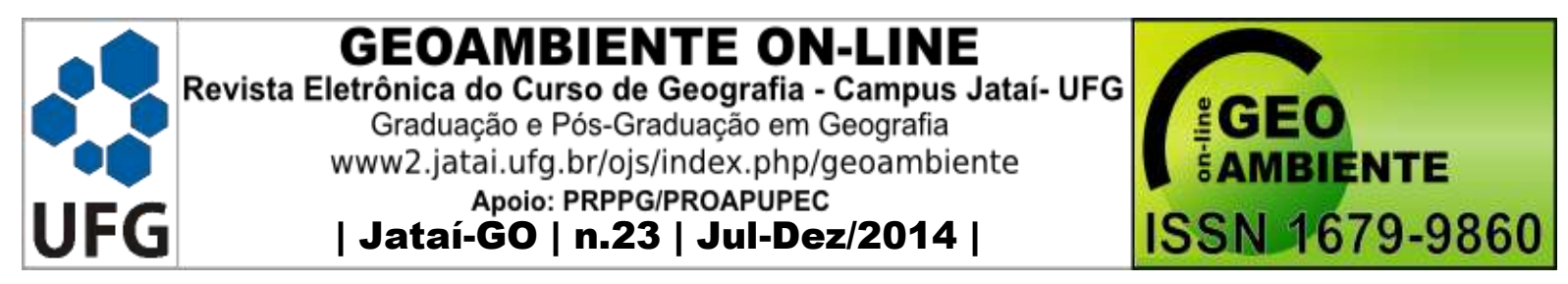

\title{
QUANTIFICAÇÃO E DISTRIBUIÇÃO ESPACIAL DE ELEMENTOS GEOQUÍMICOS EM UMA ÁREA AGRÍCOLA NO MUNICÍPIO DE IGUARAÇU - PR
}

Valter Antonio Becegato ${ }^{1}$, Josiani Córdova Oliveira $^{2}$, Vitor Rodolfo Becegato ${ }^{3}$, Flávio José

\section{Simioni $^{1}$}

(1 - Universidade do Estado de Santa Catarina - UDESC, Departamento de Engenharia Ambiental, Docente, valter.becegato@udesc.br; flavio.simioni@udesc.br; 2- Universidade do Estado de Santa Catarina - UDESC, Mestranda do curso de Engenharia Florestal, josiani.oliv@gmail.com; 3 - Universidade do Estado de Santa Catarina - UDESC, Acadêmico do curso de Engenharia Ambiental, vitortiburon_92@hotmail.com)

\section{RESUMO}

A presente pesquisa foi realizada em uma área agrícola submetida a plantio direto, localizada no Noroeste do estado do Paraná entre as coordenadas UTM 417.750 e 420.000 m E, 7.428.250 e 7.431.250 m N. Utilizou-se 77 pontos amostrais de solos para duas profundidades: 0-20 e 20-40 cm, totalizando 154 amostras, com o objetivo de analisar as seguintes variáveis geoquímicas: argila, $\mathrm{pH}$, fósforo $(\mathrm{P})$, potássio $(\mathrm{K})$, matéria orgânica, cálcio (Ca), magnésio $(\mathrm{Mg})$, cobre $(\mathrm{Cu})$, zinco $(\mathrm{Zn})$, ferro $(\mathrm{Fe})$ e manganês $(\mathrm{Mn})$. Foram identificados e mapeados os seguintes solos: Nitossolo Vermelho Eutrófico; Latossolo Vermelho Eutroférrico e Latossolo Vermelho Distroférrico. Os maiores valores geoquímicos obtidos para a profundidade de 0-20 cm foi para as variáveis: $\mathrm{pH}, \mathrm{Ca}, \mathrm{Mg}, \mathrm{Zn}, \mathrm{Fe}$ e Mn. Para a profundidade de 20-40 cm foi à argila. Os resultados obtidos devem ser considerados na definição de planos de amostragem do solo, bem como, no manejo da adubação da referida área, através da análise do alcance e das variabilidades horizontal e vertical dos atributos geoquímicos estudados.

Palavras-chave: Mapas, geoquímica, profundidade, adubação.

Artigo recebido para publicação em 12 de Junho de 2014

Artigo aprovado para publicação em 21 de Dezembro de 2014 


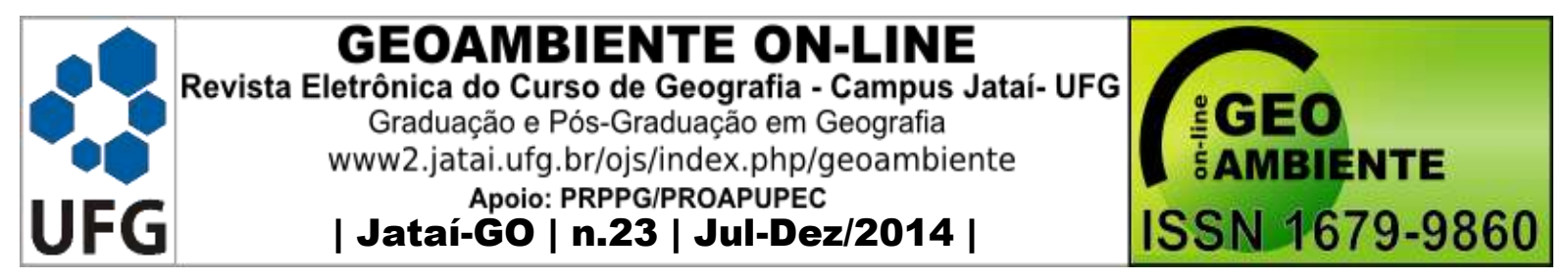

ABTSRACT

QUANTIFICATION AND SPATIAL DISTRIBUTION OF GEOCHEMICAL ELEMENTS IN AN AGRICULTURAL AREA IN THE CITY OF IGUARAÇU-PR

The present work was conducted in an agricultural area submitted to the no-till farming technique, located at the northwestern region of the state of Paraná between the UTM coordinates 417750 to $420000 \mathrm{~m} \mathrm{E}$ and 7428250 to $7431250 \mathrm{~m} \mathrm{~N}$. 77 soil sampling points were utilized for two depth ranges: 0-20 and 20-40 cm, totalizing 154 samples, with the objective of analyzing the following geochemical variables: clay, $\mathrm{pH}$, phosphorus $(\mathrm{P})$, potassium $(\mathrm{K})$, organic matter, calcium $(\mathrm{Ca})$, magnesium $(\mathrm{Mg})$, copper $(\mathrm{Cu})$, zinc $(\mathrm{Zn})$, iron (Fe) and manganese (Mn). The following soils were identified and mapped: Eutrophic Red Nitosol (Alfisoil), Eutroferric Red Latosol of clayey texture (Oxisoil) and Dystrophic Red Latosol of medium texture (Oxisoil). The highest geochemical values for the 0-20 cm depth range were obtained from the following variables: $\mathrm{pH}, \mathrm{Ca}, \mathrm{Mg}, \mathrm{Zn}, \mathrm{Fe}$ and $\mathrm{Mn}$. For the 20-40 $\mathrm{cm}$ range, the highest values were obtained from clay. The results must be considered in the definition of soil sampling plans as well as in the fertilization management of the area, through the analysis of the reach and the horizontal and vertical variabilities of the studied geochemical attributes.

Keywords: maps, geochemistry, depth, fertilization.

\section{RESUMEN}

\section{CUANTIFICACIÓN Y DISTRIBUCIÓN ESPACIAL DE ELEMENTOS GEOQUÍMICOS EN UN ÁREA AGRÍCOLA EN LA CIUDAD DE IGUARAÇU-PR}

La presente pesquisa fue realizada en un área agrícola sometida a la siembra directa, ubicada en la región noroeste del estado de Paraná entre las coordenadas UTM 417.750 hasta 420.000 m E y 7.428.250 hasta 7.431.250 m N. Fueron utilizadas 77 puntos de muestreo de suelos para dos rangos de profundidad: 0-20 cm y 20-40 cm, totalizando 154 amuestras, con el objetivo de analizar las siguientes variables geoquímicas: arcilla, $\mathrm{pH}$, fósforo $(\mathrm{P})$, potasio $(\mathrm{K})$, materia orgánica, calcio $(\mathrm{Ca})$, magnesio $(\mathrm{Mg})$, cobre $(\mathrm{Cu})$, cinc $(\mathrm{Zn})$, fierro $(\mathrm{Fe})$ y manganeso (Mn). Fueron identificados y mapeados los siguientes solos: Alfisoil y Oxisoil. Los valores geoquímicos más elevados fueron obtenidos para las siguientes variables: $\mathrm{pH}, \mathrm{Ca}, \mathrm{Mg}, \mathrm{Zn}, \mathrm{Fe}$ y Mn. Para el rango de profundidad de $20-40 \mathrm{~cm}$ los valores más elevados fueron obtenidos por la arcilla. Los resultados deben ser considerados en la definición de planos de muestreo 


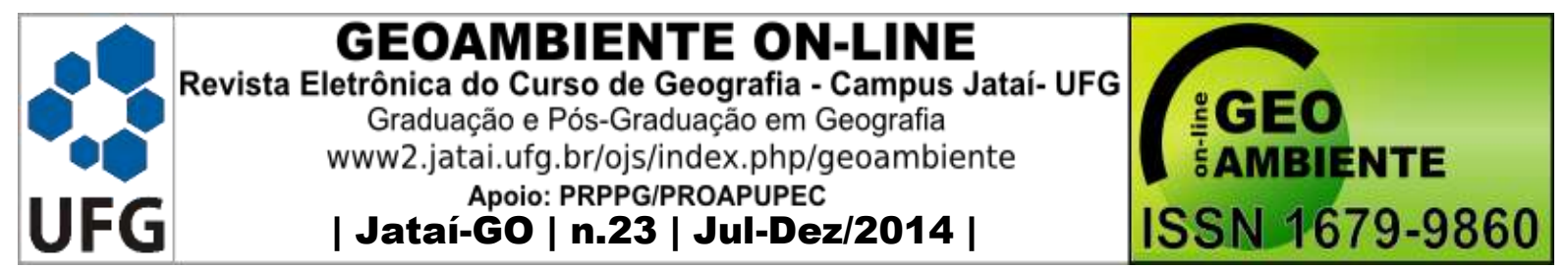

del suelo así como en la gestión de la fertilización del área, por medio del análisis del alcance y de las variabilidades horizontal y vertical de los atributos geoquímicos.

Palabras clave: mapas, geoquímica, profundidad, fertilización.

\section{INTRODUÇÃO}

O solo é constituído de minerais e poros ocupados por ar, água e material orgânico. A fração mineral pode ser constituída de partículas de tamanhos variáveis, desde argila (partículas menores que $0,004 \mathrm{~mm}$ ) até matacões (superiores a $256 \mathrm{~mm}$ ).

Os minerais do solo costumam ser separados em minerais primários e secundários. Os primários são aqueles que existem, normalmente em rochas ígneas, e podem persistir no solo. Os minerais secundários são formados pela decomposição dos minerais primários por processos químicos e recombinação em novos minerais. Podem formar-se no próprio solo ou, o que é mais comum, durante processos gerais de intemperismo e translocação de elementos químicos, dando origem às rochas sedimentares (BECEGATO e FERREIRA, 2005).

Além dos minerais de argila, que conferem cargas aos solos, outro elemento de suma importância na dinâmica de adsorção dos cátions é a matéria orgânica. Em solos tropicais e subtropicais altamente intemperizados, a matéria orgânica é de grande importância como fonte de nutrientes para as plantas, além da retenção de cátions e da complexação de elementos tóxicos e de micronutrientes, à estabilidade da estrutura, à infiltração e retenção de água, à aeração, entre outros (BAYER e MIELNICZUK, 1997).

Os solos brasileiros, em sua grande maioria, inseridos em regiões tropicais, são em geral, quimicamente pobre como decorrência de perdas constantes por lixiviação de elementos químicos como nitrogênio, fósforo e potássio, essenciais para grandes culturas como soja, trigo e cana-de-açúcar. A forma conhecida, até o momento, de repor nutrientes aos solos e, consequentemente, fornecer às plantas insumos visando à obtenção de altas produtividades é por adubação química, através de compostos denominados comercialmente de formulações NPK. Tais formulações são muito variadas nos conteúdos dos elementos retromencionados, cujas concentrações variam de acordo com a necessidade de cada solo e cultura (BECEGATO e FERREIRA, 2005).

Para o aporte de elementos como o cálcio e o magnésio, bem como, a elevação do pH em solos quimicamente pobres, utiliza-se a aplicação de calcário, rocha sedimentar que após 


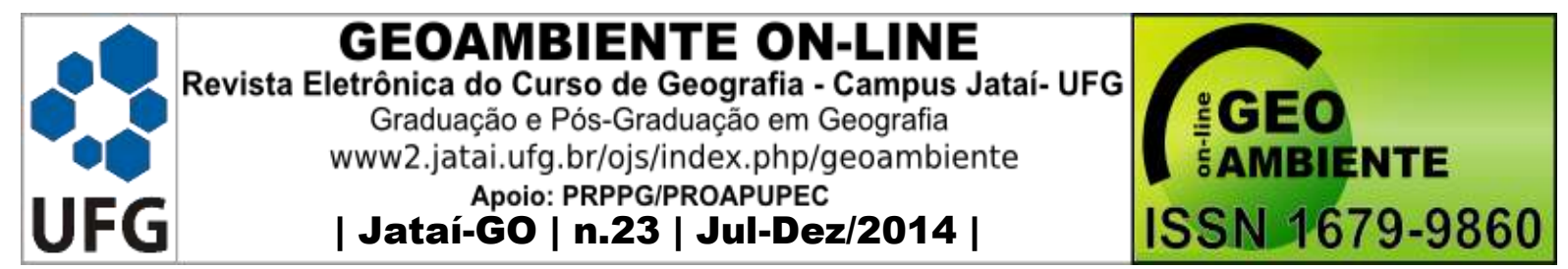

extraída das jazidas é moída o mais fina possível, para que as partículas reajam com o solo rapidamente.

O uso exagerado desses produtos tem se tornado uma atividade de risco no que concerne à adição de metais no solo e na água (TITO et al., 2012). A maior ou menor mobilidade dos metais pesados no solo é influenciada pelas características do solo e pelo teor do metal (OLIVEIRA e MATTIAZO, 2001). De acordo com Elbachá (1989) e Santos et al. (2010), o tipo de solo, a mineralogia das argilas, a distribuição granulométrica, a estrutura do solo, a capacidade de troca iônica, o tipo de íons adsorvidos e o teor de matéria orgânica, influenciam sensivelmente o transporte de contaminantes.

A presença de metais pesados muitas vezes está associada à localização de regiões agrícolas e industriais. Dos metais pesados, aqui analisados, o $\mathrm{Co}, \mathrm{Fe}, \mathrm{Mn}, \mathrm{Zn}$ podem ser tóxicos às plantas, de maneira especial quando em altas concentrações, sendo, neste caso, chamados de fitotóxicos (McBRIDE, 1994).

Sendo assim, o trabalho objetivou quantificar e espacializar a presença dos elementos acima citados e comparar com outros estudos, bem como verificar a obediência a legislação vigente em termos de concentração.

\section{MATERIAL E MÉTODOS}

\subsection{Caracterização da área}

A área situa-se no município de Iguaraçu - PR, entre as coordenadas UTM 417.750 e 420.000 m E, 7.428.250 e 7.431.250 m N. A utilização da área é por culturas anuais, sendo, soja e milho no verão e trigo no inverno, preparadas sob o sistema de plantio direto, onde não é feito o revolvimento da terra para o plantio.

O clima, de acordo com a carta climática do Paraná (IAPAR, 1978), tendo por base a classificação em Köeppen, é Cfa, ou seja, subtropical úmido mesotérmico, com verões quentes, e tendência de concentração de chuvas nos meses de verão. A precipitação média anual é de 1.492 mm/ano (RUFINO et al., 1993).

Situada no terceiro planalto Paranaense, pertencente ao Grupo Caiuá, a Formação Goio-Erê, apresenta contato transicional com a Formação Serra Geral, (FERNANDES e COIMBRA, 2000). Ainda segundo os autores, a referida formação é constituída por arenitos quartzosos, marrom-avermelhados e cinza arroxeados, finos a muito finos, mineralogicamente maturos e texturalmente submaturos. Nas partes mais altas, predominam materiais 


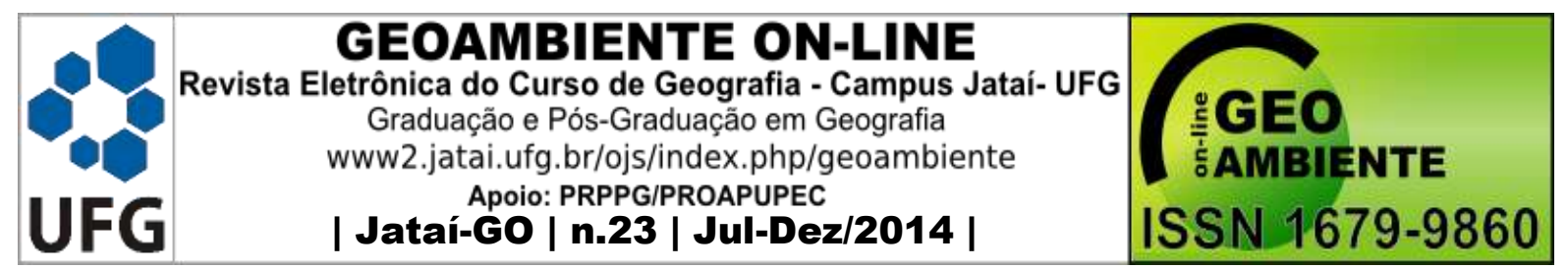

retrabalhados das formações Goio-Erê e Serra Geral, originando solos de textura mista entre arenitos quartzosos e argila. Na medida em que o relevo fica mais acidentado, predominam solos de textura argilosa, e nas drenagens, ocorrem áreas de contato com a Formação Serra Geral.

\subsection{Metodologia}

Utilizando-se trado holandês efetuou-se as coletas de 154 amostras de solos em 77 pontos para as profundidades de 0 a 20 e 20 a $40 \mathrm{~cm}$; cujos pontos foram georreferenciados pelo Sistema de Posicionamento Global - GPS, conforme ilustra a Figura 1.

Figura 1. Malha de amostragem dos pontos de coleta de solos.

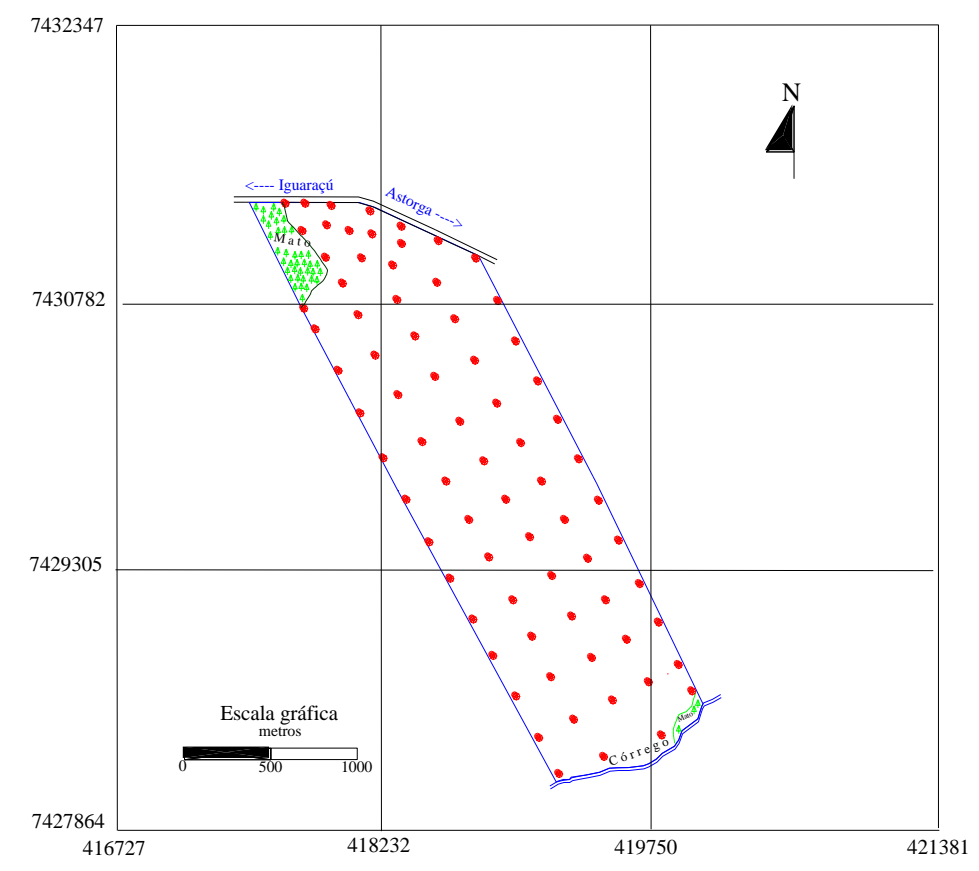

As amostras coletadas foram armazenadas em sacos de polietileno. Após secas ao ar livre, foram passadas em peneiras de náilon com abertura de $2 \mathrm{~mm}$. A alíquota desse material foi macerada em almofariz de ágata e passada em peneiras de $0,3 \mathrm{~mm}$ de abertura (ABNT $\mathrm{n}^{\circ} 50$ ), com malha de aço inoxidável, visando evitar contaminações.

As análises físicas e químicas seguiram as orientações descritas no Manual de adubação e calagem para os estados do Rio Grande do Sul e Santa Catarina (2004). 


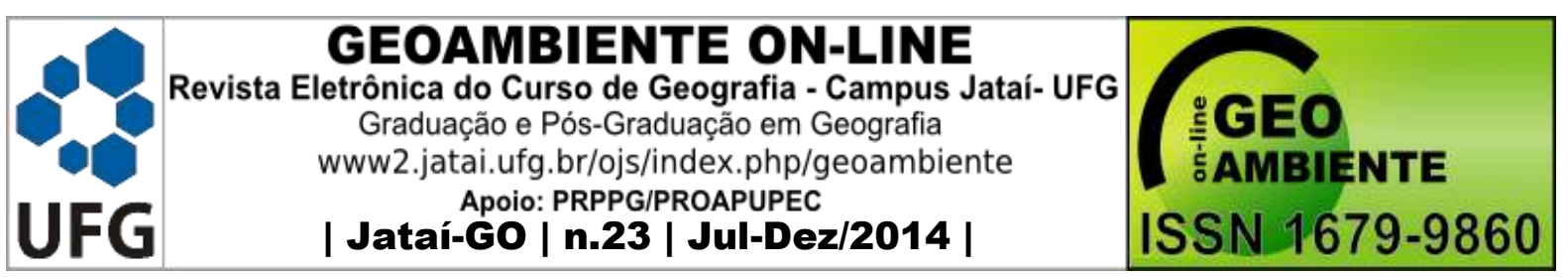

A interpolação e espacialização dos dados foram efetuadas por meio do software SURFER ${ }^{\circledR}$ para processamento de dados georreferenciados pelo Sistema de posicionamento Global (GPS).

\section{RESULTADOS E DISCUSSÃO}

Os solos mapeados na área estão na Figura 2. O Nitossolo Vermelho Eutrófico de textura argilosa, derivado de rochas basálticas, cuja inserção espacial se dá mais próximo aos canais de drenagens, com relevo mais acidentado; Latossolo Vermelho Eutroférrico é um solo mais velho comparativamente ao anterior, de textura argilosa, mais profundo, também originado de rochas eruptivas básicas situado em relevo suave ondulado à praticamente plano e, por fim, o Latassolo Vermelho Distrófico, oriundo do retrabalhamento das formações Serra Geral e Goio-Erê, cujos teores de argila estão entre 16 e 35\%, considerado pedologicamente de textura média, espacialmente distribuído em relevo praticamente plano.

Figura 2. Distribuição espacial dos solos mapeados

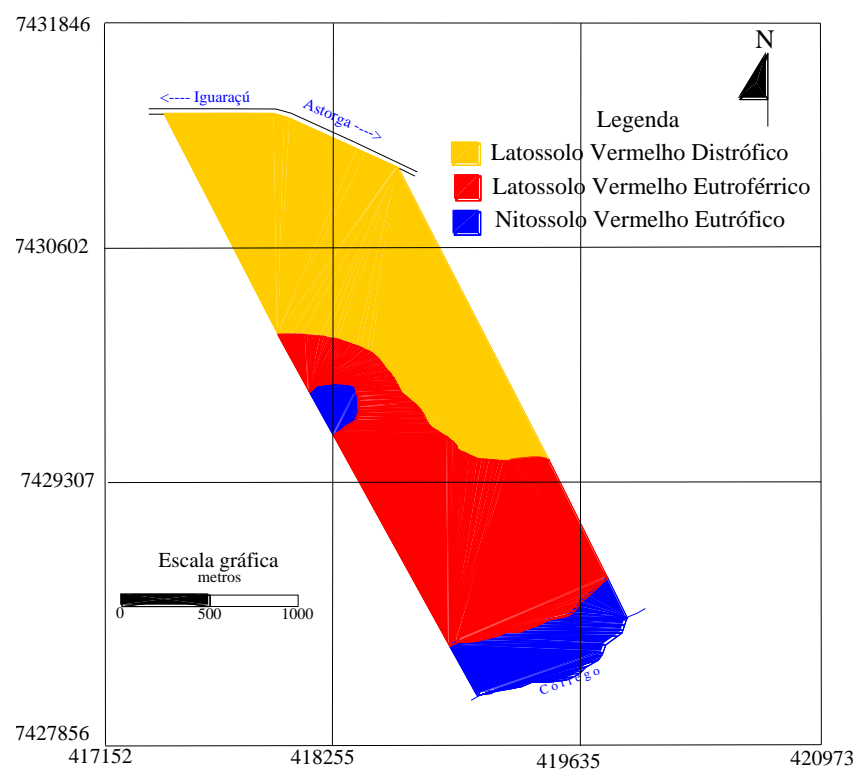

Observou-se diferença significativa apenas nos teores médios de argila, P, K, matéria orgânica, Zn, Fe e Mn entre as profundidades estudadas (Tabelas 1 e 2). Maiores teores de P, $\mathrm{K}$, matéria orgânica, $\mathrm{Zn}$, Fe e $\mathrm{Mn}$ foram encontrados nos primeiros $20 \mathrm{~cm}$ do solo, ao contrário da argila. Os dados aqui obtidos foram comparados aos de um levantamento geoquímico multielementar realizado no Estado do Paraná (Mineropar, 2005), onde, apenas a 


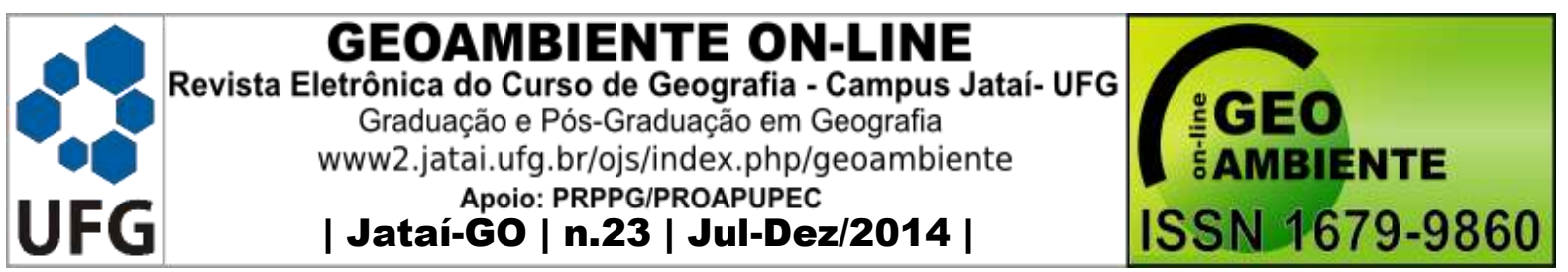

variável $\mathrm{pH}$, para ambas as profundidades, ficou acima da média do estudo. Os valores de $\mathrm{Zn}$

e $\mathrm{Cu}$ estão dentro do limite estabelecido pela Resolução CONAMA n. 420/2009, a qual dispõe sobre a qualidade do solo quanto a presença de substâncias químicas.

Nas Tabelas 1 e 2 encontram-se as estatísticas dos dados para as profundidades 0-20 e 20-40 cm. Analisando-se os dados da argila, observa-se que os valores médios foram de $39,3 \%$ e $44,7 \%$, respectivamente, evidenciando que a mesma aumenta com a profundidade, em decorrência da litologia, notadamente da Formação Serra Geral. Tais percentagens mudam significativamente, tomando-se por base os solos argilosos com percentual médio de argila com $73,58 \%$ e o de textura mista com $25,2 \%$. A distribuição espacial da argila para as duas profundidades pode ser vista na Figura 3.

Figura 3. Distribuição espacial da Argila: A) profundidade $0-20 \mathrm{~cm}$, B) profundidade: 20 $40 \mathrm{~cm}$

A)

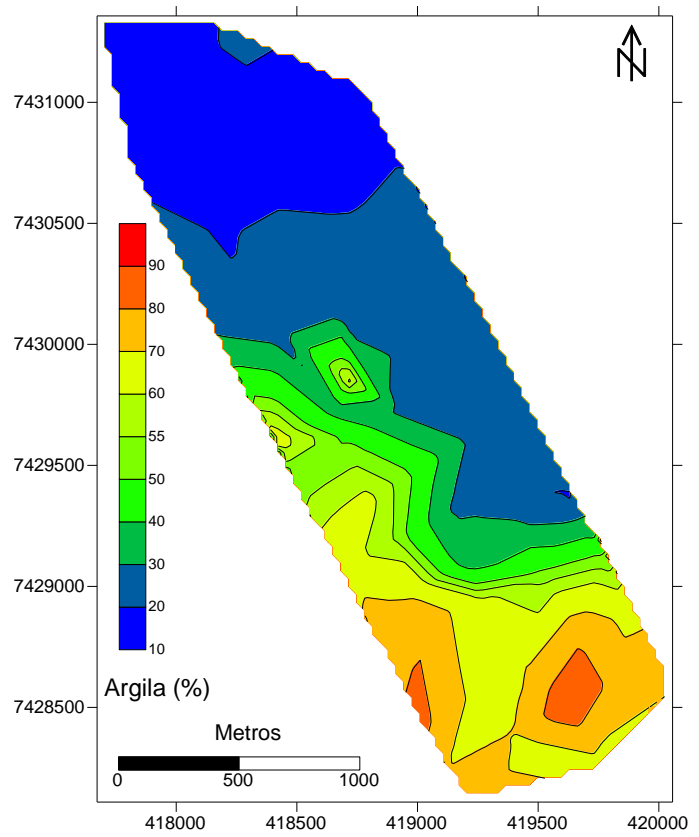

B)

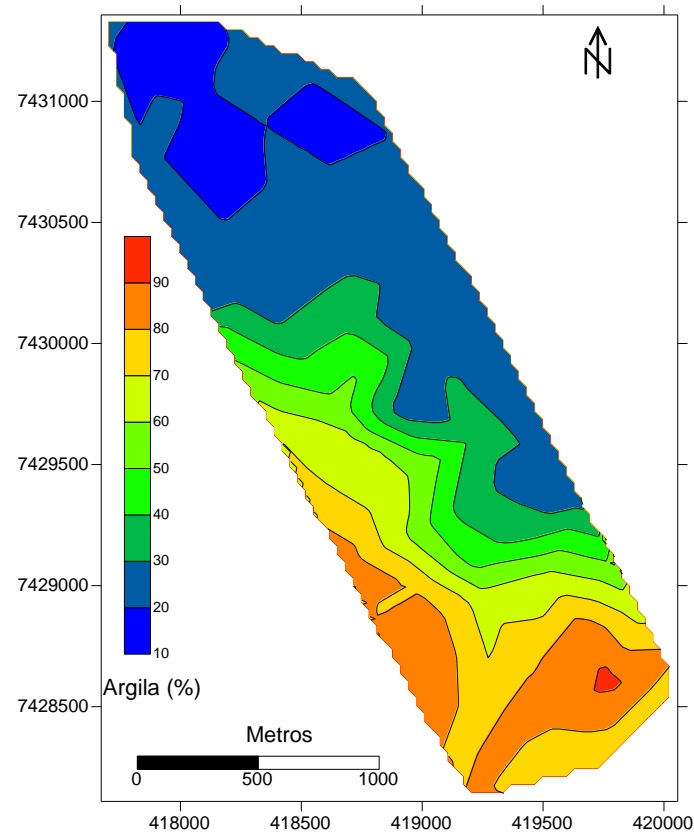




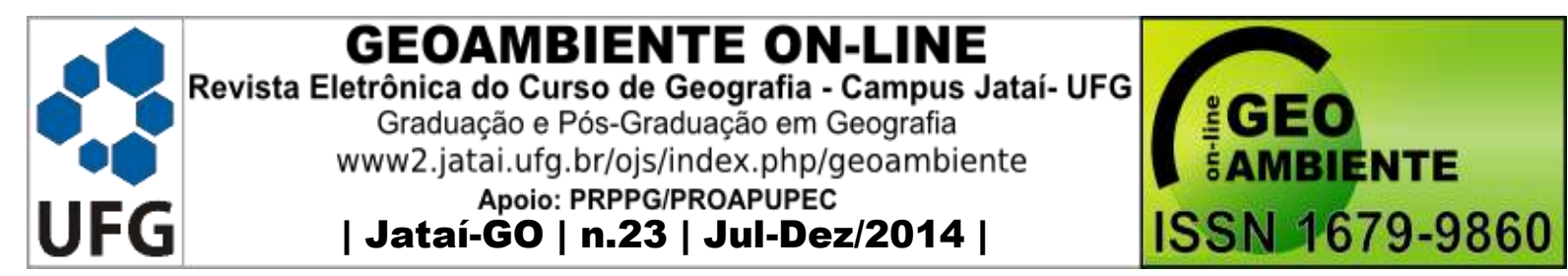

Tabela 1. Estatística descritiva dos parâmetros geoquímicos para a profundidade de $0-20 \mathrm{~cm}$ em 77 amostras.

\begin{tabular}{|c|c|c|c|c|c|c|c|c|c|c|c|}
\hline & $\begin{array}{c}\text { Argila } \\
(\%)\end{array}$ & $\begin{array}{c}\mathrm{pH} \\
(\mathrm{SMP})\end{array}$ & $\begin{array}{c}\mathrm{P} \\
(\mathrm{ppm})\end{array}$ & $\begin{array}{c}\mathrm{K} \\
(\mathrm{ppm})\end{array}$ & $\begin{array}{l}\text { Matéria } \\
\text { orgânica }\end{array}$ & Cálcio & $\begin{array}{l}\text { Magnésio } \\
\mathrm{ol}_{\mathrm{d}} / \mathrm{dm}^{3}\end{array}$ & Cobre & Zinco & $\begin{array}{l}\text { Ferro } \\
/ \text { L solo) }\end{array}$ & Manganês \\
\hline Mínimo & 14 & 5,7 & 1,8 & 36 & 0.6 & 0,2 & 0.1 & 0,8 & 0.5 & 29 & 30 \\
\hline Máximo & 88 & 7,2 & 80 & 667 & 4,6 & 9,6 & 2,7 & 25,9 & 23,5 & 112 & 76 \\
\hline Média & $39,3(\mathbf{a})$ & $6,3(c)$ & $19,1(d)$ & $155,4(f)$ & $2,1(h)$ & $3,2(1)$ & $0,78(\mathrm{~m})$ & $7,4(n)$ & $4,8(0)$ & $57,8(q)$ & $58,9(s)$ \\
\hline Desvio padrão & 23,4 & 0,33 & 18,8 & 117,2 & 1,06 & 2,6 & 0,6 & 7,0 & 4,5 & 25,78 & 16,5 \\
\hline Coeficiente de variação (\%) & 59,6 & 5,2 & 98,4 & 75 & 51,3 & 81,3 & 77 & 94,6 & 94 & 44,6 & 27,94 \\
\hline Assimetria & 0,60 & 0,57 & 1,6 & 1,65 & 0,71 & 0,97 & 0,89 & 1,05 & 2,0 & 1,51 & $-0,86$ \\
\hline Curtose & 1,26 & 0,24 & 2,3 & 4 & $-0,48$ & $-0,24$ & $-0,02$ & 0,14 & 4,14 & 1,62 & $-0,46$ \\
\hline
\end{tabular}

Tabela 2. Estatística descritiva dos parâmetros geoquímicos para a profundidade de 20 - $40 \mathrm{~cm}$ em 77 amostras.

\begin{tabular}{|c|c|c|c|c|c|c|c|c|c|c|c|}
\hline & $\begin{array}{c}\text { Argila } \\
(\%)\end{array}$ & $\begin{array}{c}\mathrm{pH} \\
\text { (SMP) }\end{array}$ & $\begin{array}{c}\mathrm{P} \\
(\mathrm{ppm})\end{array}$ & $\begin{array}{c}\mathrm{K} \\
(\mathrm{ppm})\end{array}$ & $\begin{array}{l}\text { Matéria } \\
\text { orgânica }\end{array}$ & $\begin{array}{l}\text { Cálcio } \\
----\mathrm{cl}^{2}\end{array}$ & $\begin{array}{l}\text { Magnésio } \\
\mathrm{ll}_{\mathrm{C}} / \mathrm{dm}^{3} \text {---. }\end{array}$ & Cobre & $\begin{array}{l}\text { Zinco } \\
----(m\end{array}$ & $\begin{array}{l}\text { Ferro } \\
\text { /L solo) }\end{array}$ & Manganês \\
\hline Mínimo & 14 & 5,7 & 1 & 24 & 0,5 & 0,3 & 0,1 & 0,7 & 0,5 & 2,5 & 2,3 \\
\hline Máximo & 92 & 7,3 & 60 & 364 & 4,3 & 10,1 & 2,7 & 28,8 & 21,3 & 147,7 & 99,7 \\
\hline Média & $44,7(b)$ & $6,4(c)$ & $6,9(e)$ & $106,79(\mathrm{~g})$ & $1,749(i)$ & 2,9(1) & $0,74(m)$ & 7,9(n) & $3,0(p)$ & $44,16(r)$ & $33,88(t)$ \\
\hline Desvio padrão & 25,8 & 0,25 & 8,3 & 82,5 & 0,94 & 2,46 & 0,57 & 7,44 & 3,73 & 25,93 & 20,66 \\
\hline Coeficiente de variação (\%) & 57,7 & 3,9 & 119,1 & 77,4 & 54,3 & 84,8 & 77 & 94,1 & 123 & 58,7 & 60,9 \\
\hline Assimetria & 0,53 & 0,45 & 4,14 & 1,19 & 0,83 & 1,27 & 0,93 & 1,1 & 2,57 & 1,88 & 0,97 \\
\hline Curtose & $-1,35$ & 1,85 & 22,4 & 0,55 & $-0,08$ & 0,76 & 0,44 & 0,48 & 7,73 & 4,33 & 0,74 \\
\hline
\end{tabular}




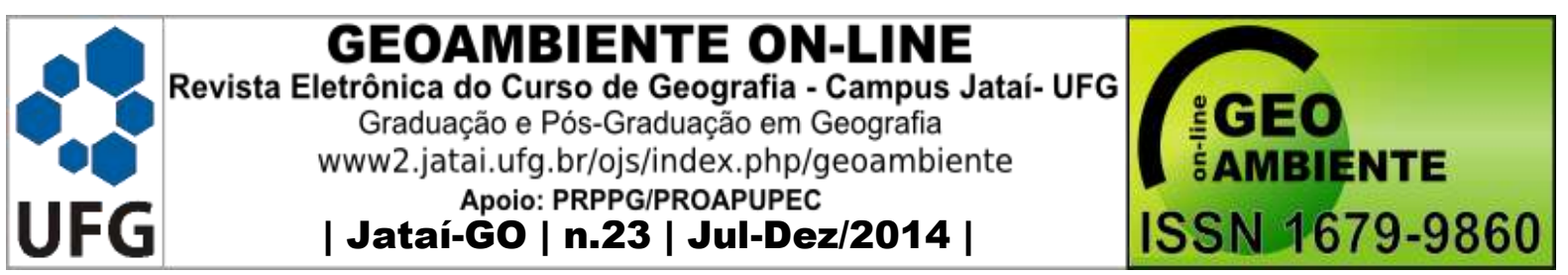

$\mathrm{O} \mathrm{pH}$ do solo é influenciado por vários fatores, incluindo o material de origem, a precipitação, a decomposição da matéria orgânica e a adubação nitrogenada. Um solo originado de rocha básica, geralmente terá valores de $\mathrm{pH}$ mais altos do que aqueles formados por rochas ácidas. Segundo Borges Júnior et al., (2008), o pH é uma característica do solo importante na disponibilidade dos metais, já que controla a precipitação, a dissolução de carbonatos e hidróxidos, além da hidrólise de vários compostos orgânicos.

A distribuição espacial do pH solos pode ser observada na Figura 4. As diferenças nos valores para as duas profundidades não diferem significativamente, a julgar pelas respectivas médias 6,3 e 6,4 (Tabelas 1 e 2); contudo, espacialmente, verifica-se que há uma distribuição irregular para ambas as profundidades. Os tratos de valores mais baixos coincidem com os solos argilosos. Enquanto o valor mínimo de pH é de 5,7 para as duas profundidades, cujos valores médios das mesmas, estão acima de 6,0, ocorrendo esporadicamente alguns pontos com valores próximos ao mínimo.

Figura 4. Distribuição espacial do pH: A) profundidade 0 - $20 \mathrm{~cm}, \mathrm{~B}) 20-40 \mathrm{~cm}$

A)

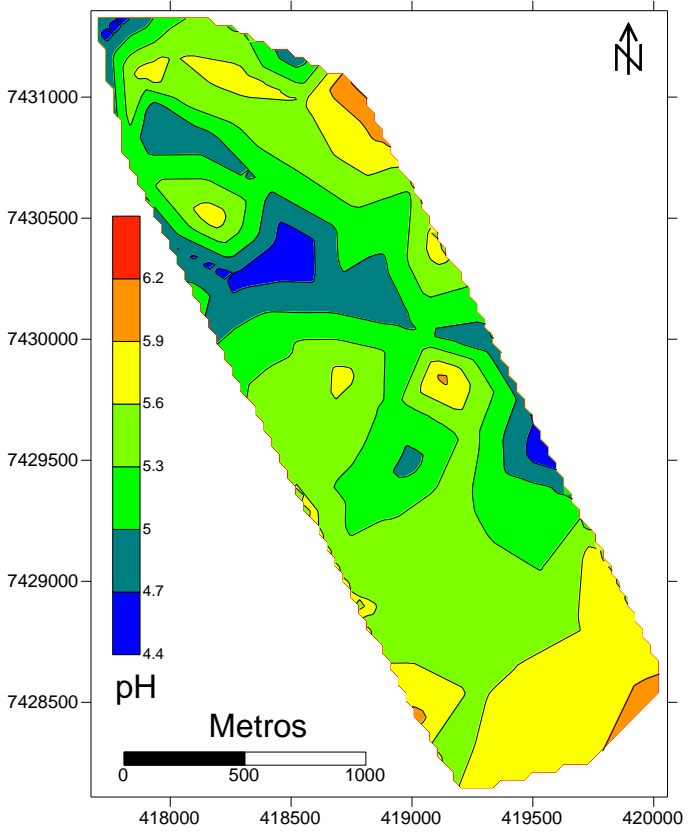

B)

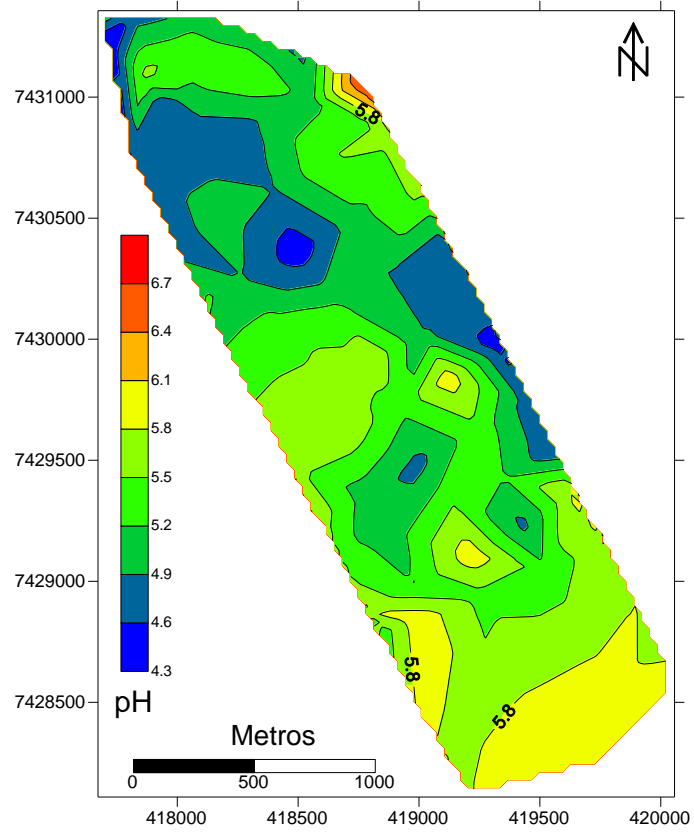

Os segmentos com valores mais elevados no solo areno/argiloso - Latossolo Vermelho Distrófico, possivelmente se devem há aplicações de calcário com maior frequência. Neste 


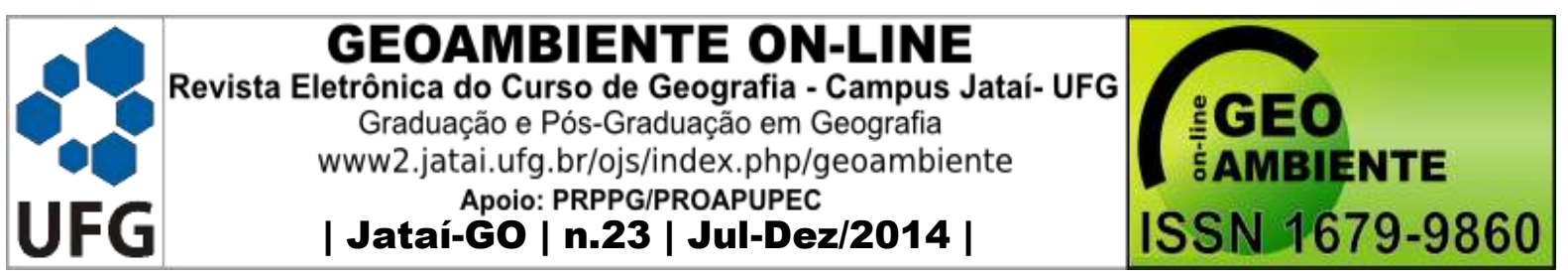

caso, a possível explicação reside no fato de que pode estar havendo maior perda de bases ao longo do perfil deste solo, como decorrência da aplicação de calcário num intervalo de 4 a 5 anos para a correção da acidez de tais solos.

Os mapas com a espacialização dos teores de $\mathrm{Ca}$ e $\mathrm{Mg}$, para as duas profundidades, estão expressos nas Figuras 5 a 6 . O mapa do Ca para a profundidade de $20-40 \mathrm{~cm}$ e os do $\mathrm{Mg}$ para as duas profundidades denotam boa correlação com a unidade de mapeamento Nitossolo Vermelho Eutrófico. Tal solo, originado de rochas eruptivas básicas, ricas em minerais ferromagnesianos e aplicação de calcário, muito contribui para a elevação dos teores dos elementos retromencionados, na medida em que aumenta a profundidade, havendo, portanto, contribuição da rocha na medida em que a mesma vai se decompondo física e quimicamente.

Figuras 5. Distribuição espacial do Cálcio: A) profundidade $0-20 \mathrm{~cm}, \mathrm{~B}) 20-40 \mathrm{~cm}$

A)

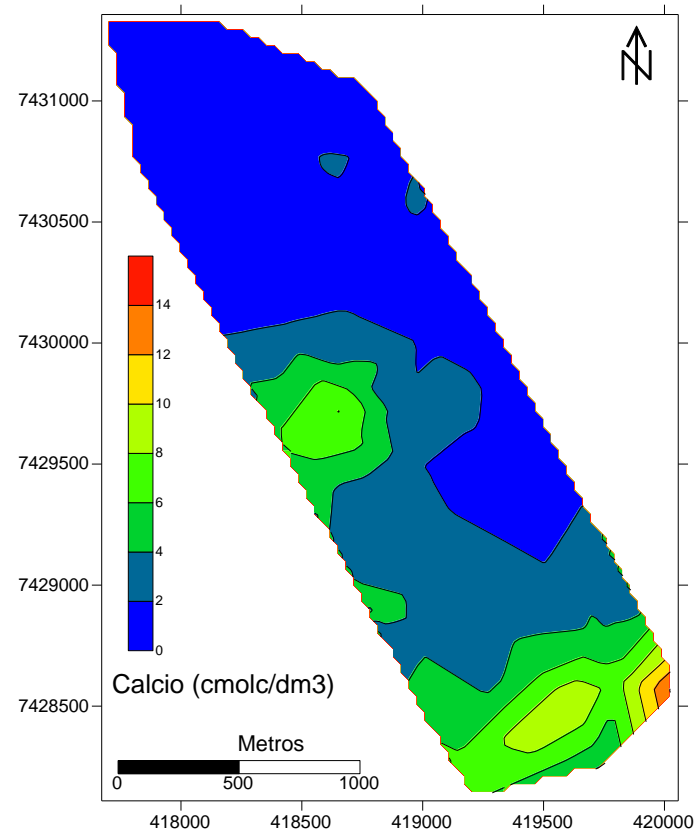

B)

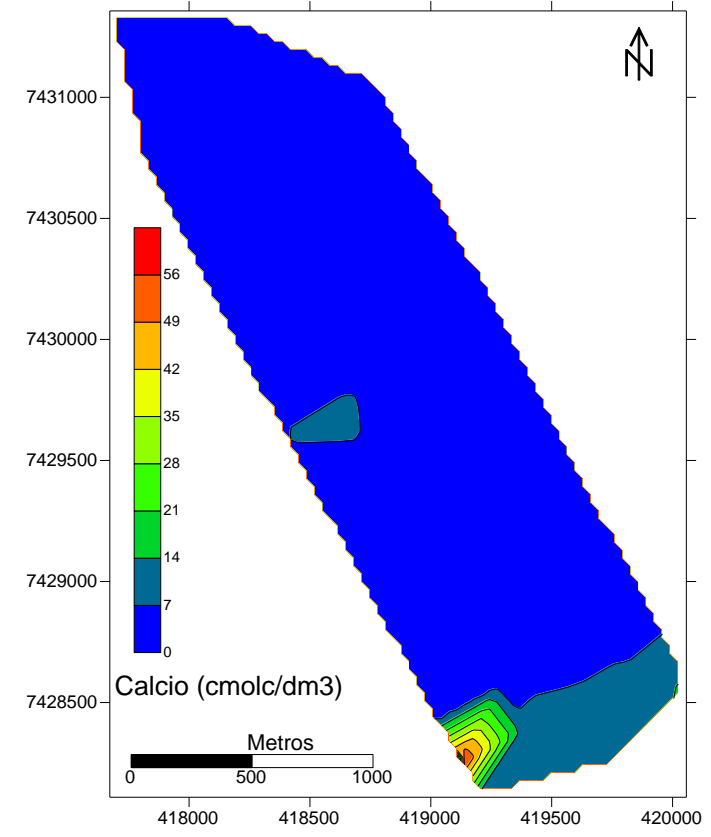




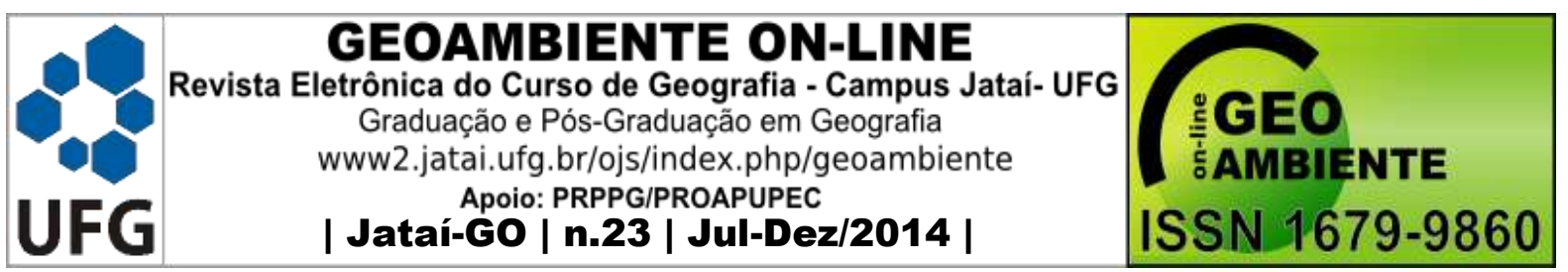

Os óxidos de Fe imprimem aos solos uma coloração vermelha e o incremento de seus teores acarreta uma cor vermelha escura (Nitossolo Vermelho Eutrófico e o Latossolo Vermelho Férrico). A incorporação de metais nas fases de óxidos de Fe é observada para uma grande variedade de metais de transição (FORD et al., 1997; MARTINEZ e MCBRIDE, 1998).

$\mathrm{Na}$ Figura 8 observa-se a distribuição espacial do $\mathrm{P}$ para as profundidades investigadas, o qual teve alguns picos na área de ocorrência do Latassolo Vermelho Distrófico, sendo que, para a profundidade de 20 - $40 \mathrm{~cm}$ observa-se valores mais reduzidos.

Figura 8. Distribuição espacial do Fósforo: A) profundidade $0-20 \mathrm{~cm}$, B) $20-40 \mathrm{~cm}$.

A)

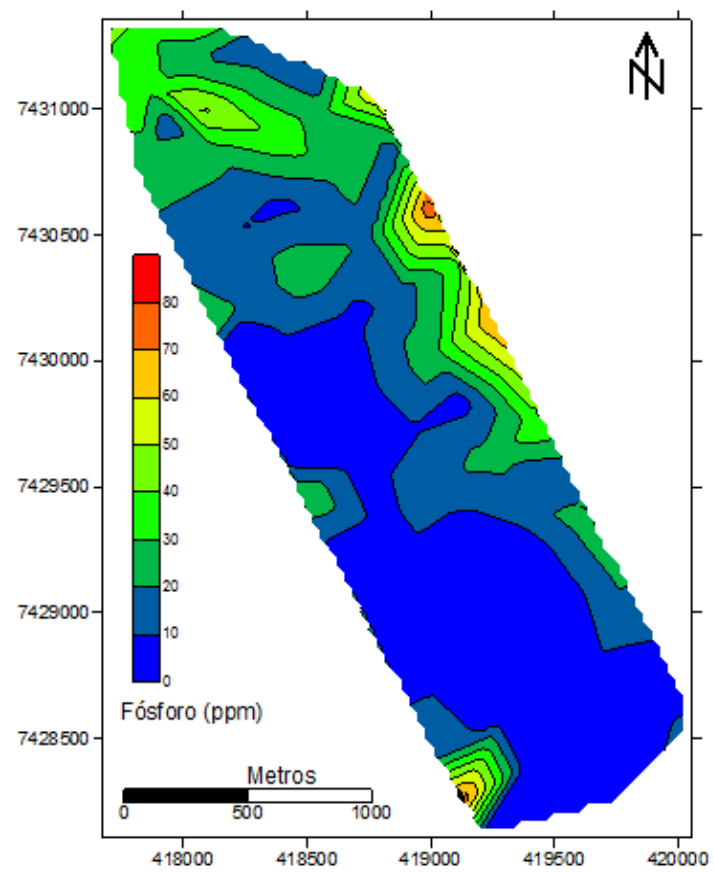

B)

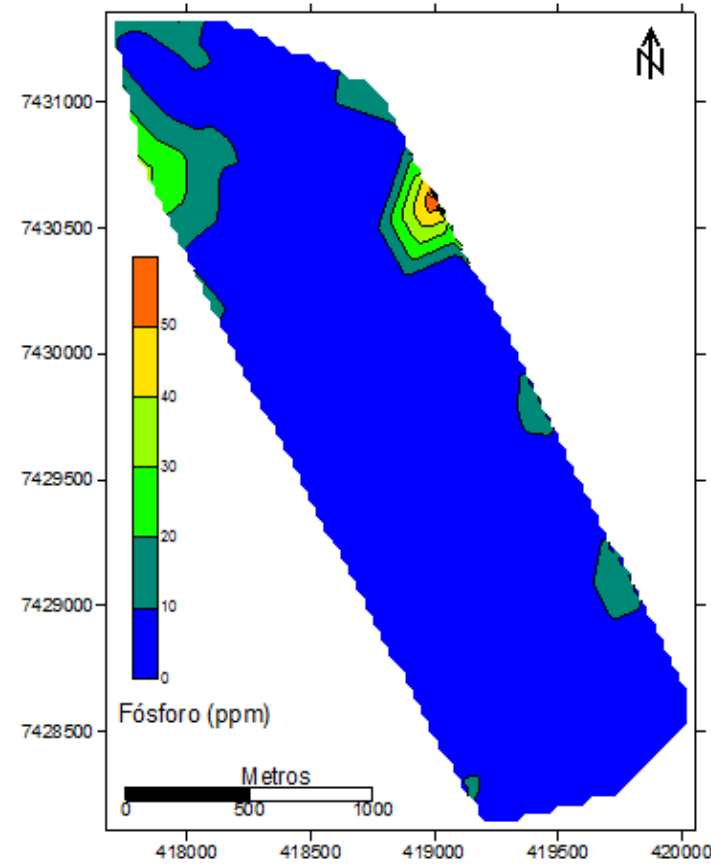

O P é considerado um elemento de baixa mobilidade nos solos. Entretanto, para o pH na faixa de 6, como no presente caso, além de ser benéfico para as plantas, traz um efeito neutralizador para os elementos tóxicos como alumínio e manganês, aumentando a solubilidade do fósforo, provocando a diminuição na capacidade de retenção deste elemento principalmente em solos argilosos e com altos teores de óxidos - hidróxidos de $\mathrm{Fe}$ e $\mathrm{Al}$ (FIGUEIREDO, 1985). Também reage com o cálcio, formando compostos pouco solúveis (SANYAL e DEDATTA, 1991). 


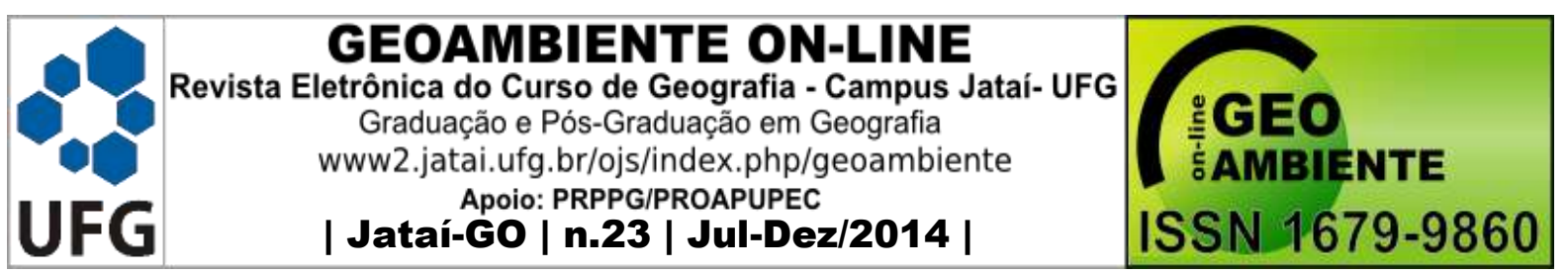

Após a aplicação dos adubos fosfatados, o P migra do adubo para o solo, onde iniciam as reações de adsorção e precipitação, entre o fosfato e os constituintes do solo (SAMPLE et al., 1980). Em solos com pH baixo, o $\mathrm{P}$ se liga principalmente com o ferro e alumínio, na forma de precipitados amorfos (LINDSAY et al., 1962).

A Figura 9 indica que as maiores concentrações do $\mathrm{K}$ para as duas profundidades, foram encontradas nas partes mais argilosas onde ocorrem o Nitossolo Vermelho Eutrófico e o Latossolo Vermelho Eutroférrico. Tais concentrações podem ser explicadas pela maior facilidade como este íon se fixa nas estruturas dos argilominerais, bem como pelo maior teor de matéria orgânica destes em relação ao solo areno-argiloso (BECEGATO, 2005). Possivelmente, as perdas de K por lixiviação são mais intensas no solo arenoso, visto que possui menor capacidade de retenção deste elemento (WERLE et al., 2008).

Figura 9. Distribuição espacial do Potássio: A) profundidade $0-20 \mathrm{~cm}$, B) $20-40 \mathrm{~cm}$

A)

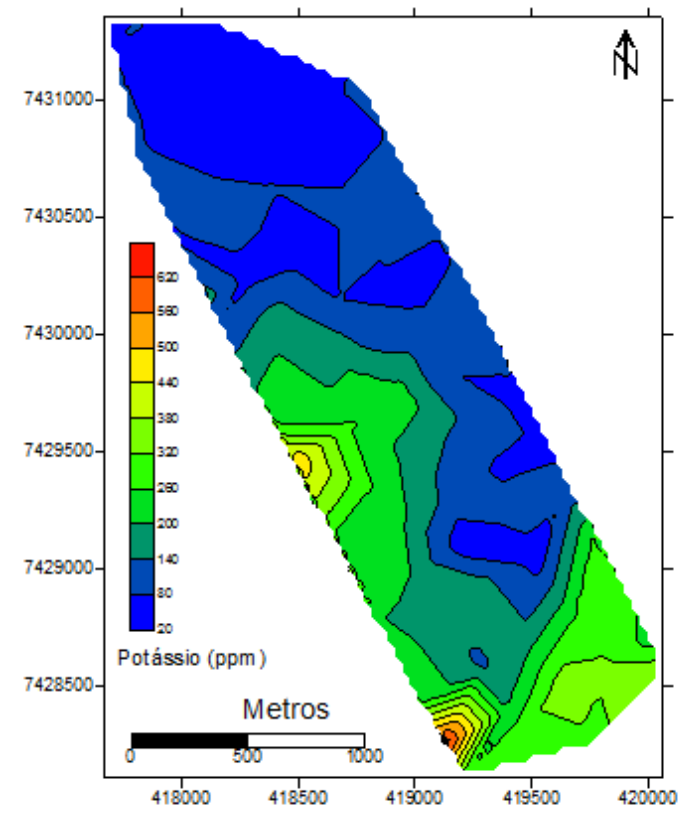

B)

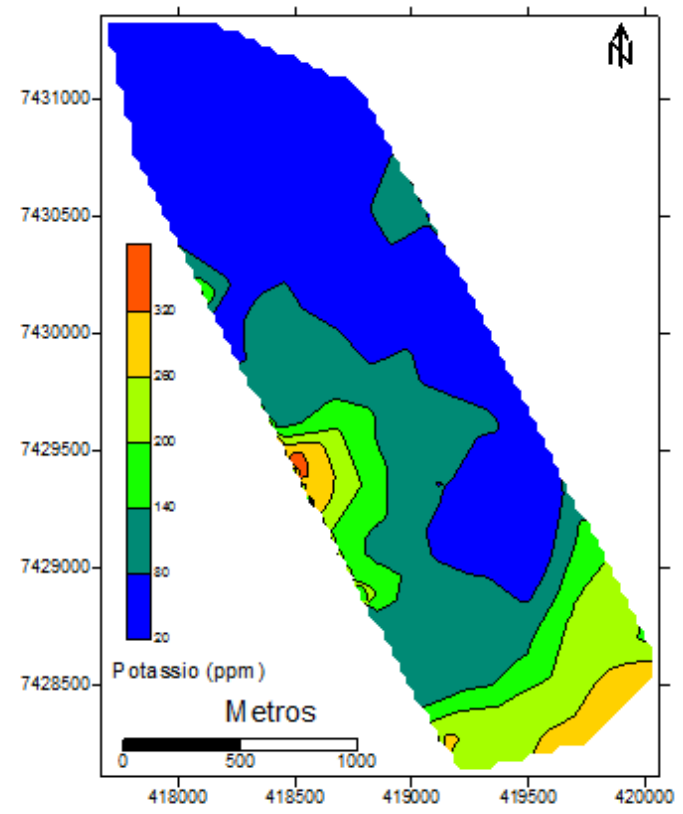

Na Figura 10 identificam-se os níveis de Mn para ambas as profundidades. Percebe-se que, nos dois casos, os maiores valores concentraram-se nas áreas de ocorrência do Latossoto Vermelho Eutroférrico, cuja área na distribuição espacial é muito semelhante a que foram encontrados os teores mais elevados de matéria orgânica, uma vez que esta é uma das principais fontes deste nutriente no solo (ZANÃO JÚNIOR et al., 2007). Em geral, os teores 


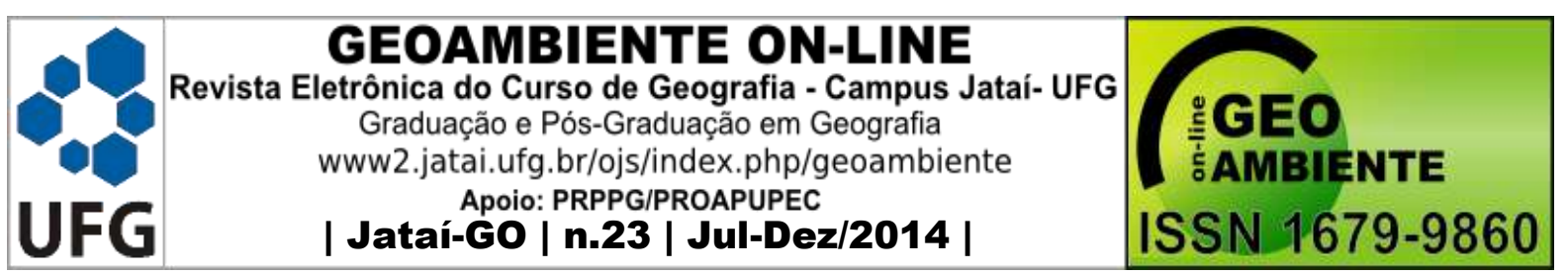

De acordo com a Figura 11, os níveis de Cu para ambas as profundidades foram mais elevados na área de ocorrência do Nitossolo Vermelho Eutrófico, solo de textura argilosa. Segundo Alloway (1990), o pH também exerce uma forte influência na dinâmica do Cu e do $\mathrm{Zn}$ no solo. Ambientes ácidos determinam uma maior mobilidade dos metais no solo, enquanto que condições de $\mathrm{pH}$ acima de seis favorecem a sua retenção, principalmente em solos com elevado grau de intemperização, onde os grupos funcionais de superfície dos componentes coloidais são, na sua maioria, pH dependentes (SODRÉ et al., 2001).

Figura 11. Distribuição espacial do Cobre: A) profundidade $0-20 \mathrm{~cm}$, B) $20-40 \mathrm{~cm}$

A)

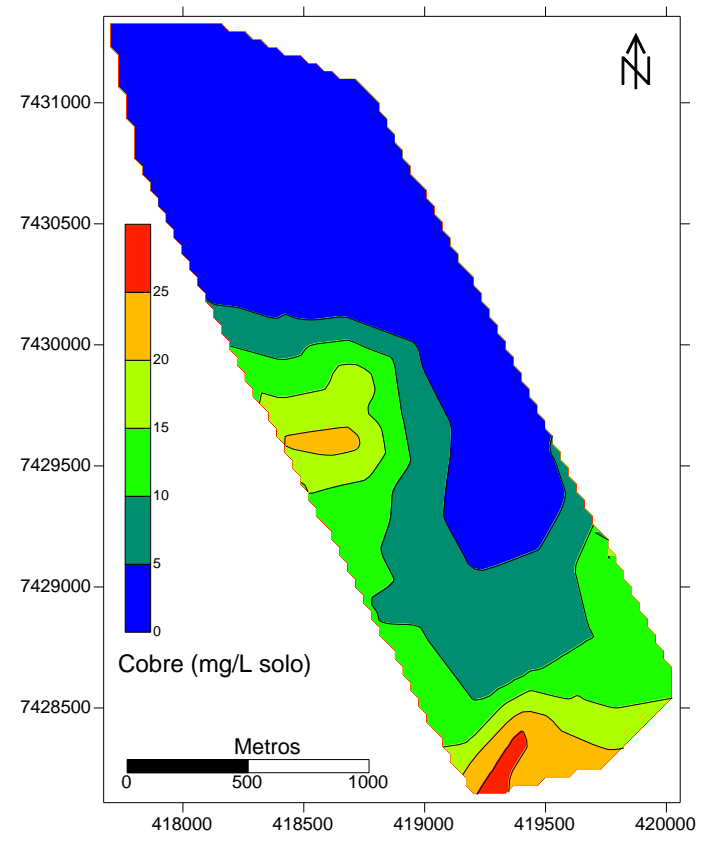

B)

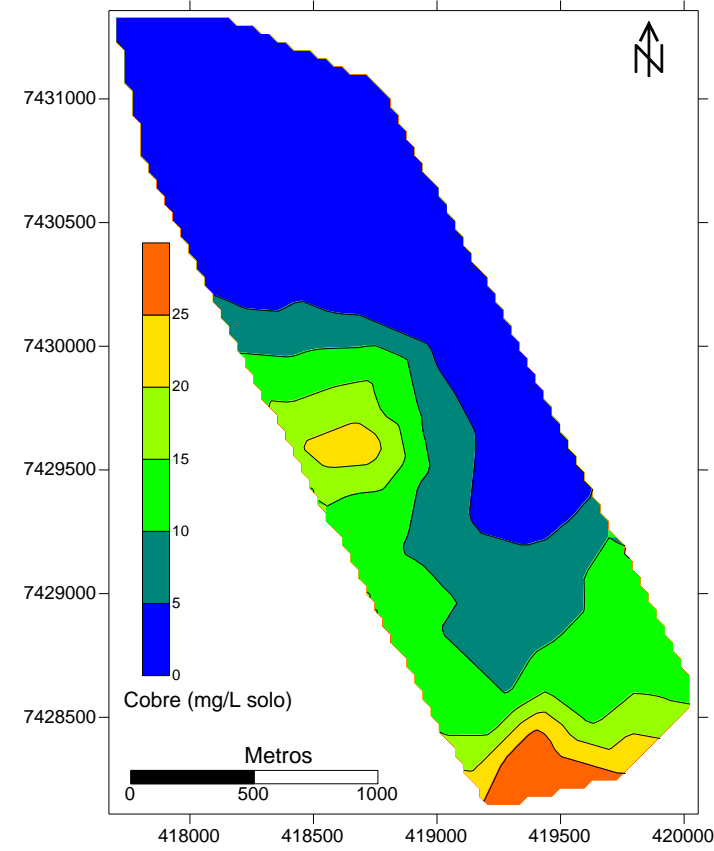

O suprimento de Zn pelo solo depende do material de origem e dos demais fatores que afetam sua concentração na solução, dentre eles a concentração de fósforo (Hamilton et al., 1993), o pH (MA e LINDSAY, 1993; ANDREOTTI et al., 2001), os teores de argila (CUNHA et al., 1994), de matéria orgânica (HAMILTON et al., 1993; Amaral Sobrinho et al. 1997) e de óxidos e hidróxidos (CUNHA et al., 1994; AMARAL SOBRINHO et al., 1997). A elevação do pH do solo diminui a concentração de Zn na solução (ARIAS et al., 2005).

Conforme têm-se na Figura 12, os picos da ocorrência de Zn são maiores na área do Nitossolo Vermelho Eutrófico - textura argilosa, semelhante ao encontrado para o cobre. 


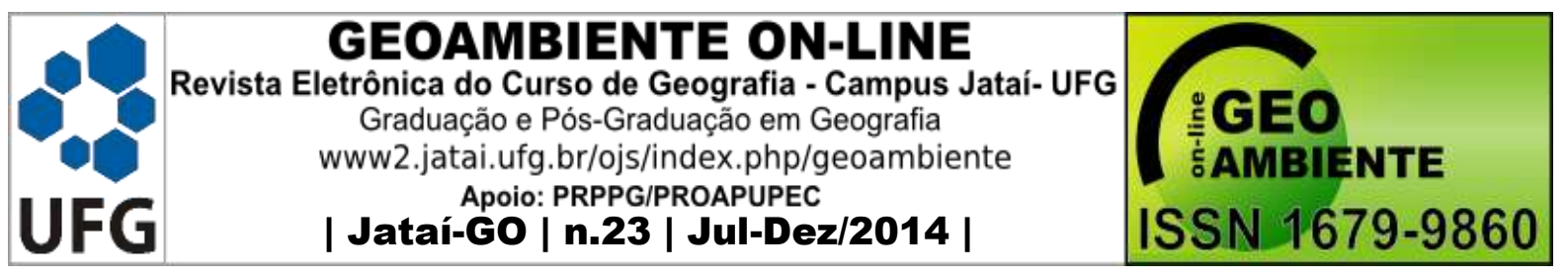

Figura 13. Distribuição espacial da Matéria Orgânica: A) profundidade $0-20 \mathrm{~cm}$, B) $20-40$ $\mathrm{cm}$

A)

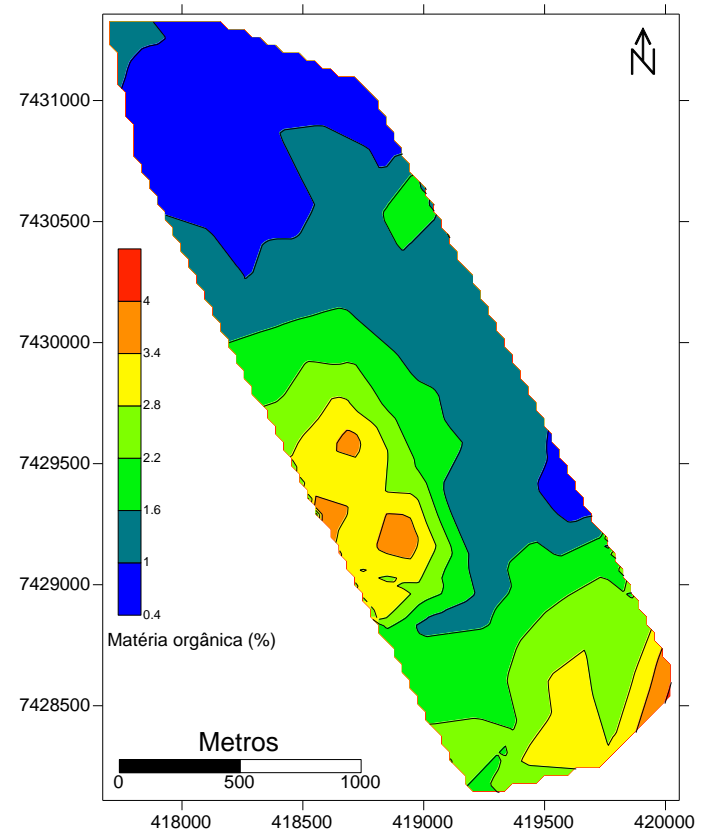

B)

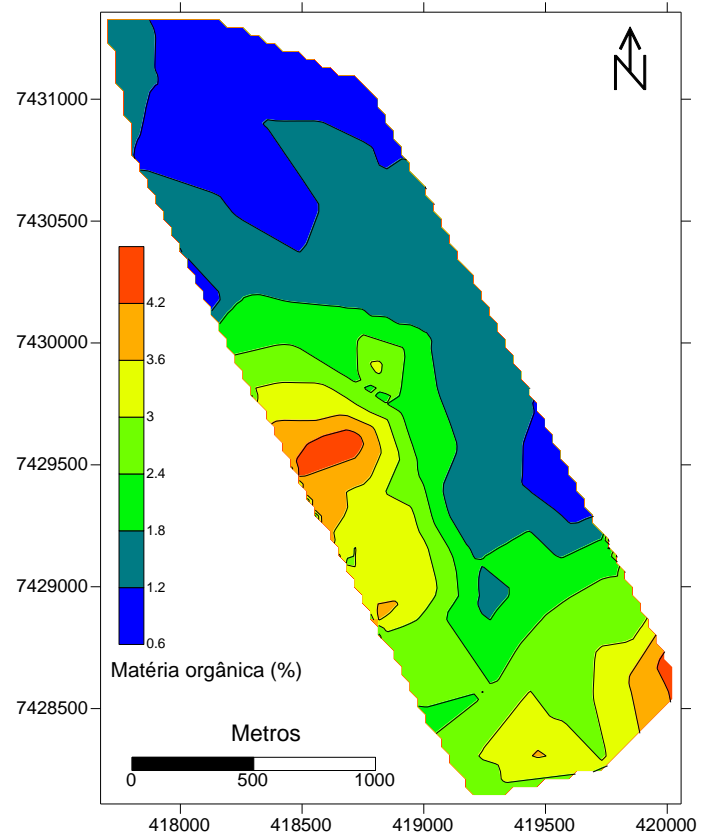

\section{Considerações Finais}

Os maiores teores de P, K, matéria orgânica, Zn, Fe e Mn foram encontrados nos primeiros $20 \mathrm{~cm}$ do solo, enquanto que para a argila, foi na camada de $20-40 \mathrm{~cm}$.

Em comparação com Mineropar (2005), apenas o pH ficou acima dos valores apresentados, para ambas as profundidades. De acordo com a Resolução CONAMA 420/2009, Zn e Cu encontram-se abaixo dos valores de investigação.

\section{Referências Bibliográficas}

ALLOWAY, B. J. Heavy metals in soil. New York: John Wiley, 1990. 339p.

AMARAL SOBRINHO, N. M. B.; GOMES, M. F.; VELlOSO, A. C. X.; OLIVEIRA, C. de. Fracionamento de zinco e chumbo em solos tratados com fertilizantes e corretivos. Revista Brasileira de Ciência do Solo, Campinas, v. 21, p. 17-21, 1997.

ANDREOTTI, M.; SOUZA, E. C. A. de; CRUSCIOL, C. A. C. Componentes morfológicos e produção de matéria seca de milho em função da aplicação de calcário e zinco. Scientia Agricola, Piracicaba, v. 58, p. 321-327, 2001. 


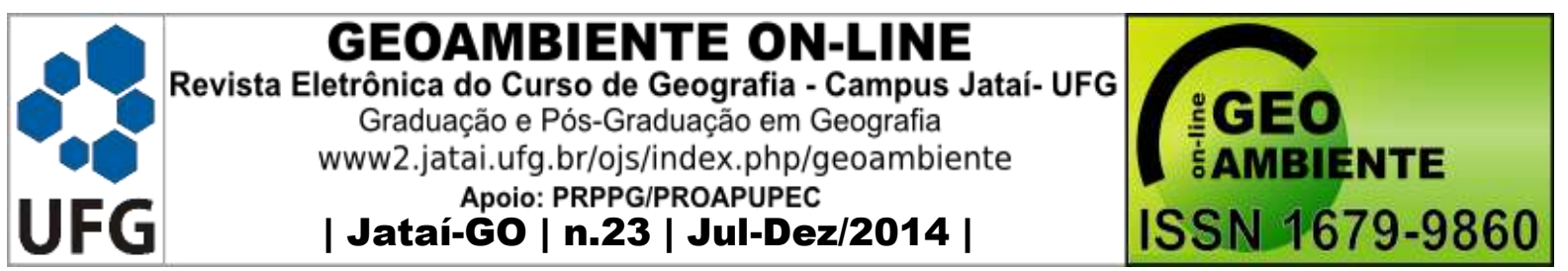

ARIAS, M.; PÉREZ-NOVO, C.; OSORIO, F.; LÓPEZ, E.; SOTO, B. Adsorption and desorption of copper and zinc in the surface layer of acid soils. Journal of Colloid and Interface Science, New York, v. 288, n. 1, p. 21-29, 2005.

BAYER, C.; MIELNICZU, J. Características químicas do solo afetadas por métodos de preparo e sistemas de cultura. Revista brasileira de Ciência do Solo, v. 21, p.105-112, 1997.

BECEGATO, V. A. Aplicação de técnicas geofísicas e geoquímicas em duas glebas agrícolas do noroeste do estado do Paraná e suas relações com fertilizantes fosfatados. Tese de Doutorado. Universidade Federal do Paraná. Curitiba. 198p. 2005.

BECEGATO, V. A; FERREIRA, F. J. F. Gamaespectrometria, resistividade elétrica e susceptibilidade magnética de solos agrícolas no noroeste do estado do Paraná. Revista Brasileira de Geofísica. vol.23 n.4 São Paulo. 2005.

BORGES JUNIOR, M.; et al. Distribuição e formas de ocorrência de zinco em solos no município de Vazante - MG. Revista Brasileira de Ciência do Solo. v. 32. p. 2183-2194. 2008. COMISSÃO DE QUÍMICA E FERTILIDADE DO SOLO (CQFS-NRS). Núcleo Regional Sul. 2004. Manual de adubação e Calagem para os Estados do Rio Grande do Sul e Santa Catarina. 1 ed. Porto Alegre, SBCS-NRS, 2004. 400p.

CUNHA, R. C.; CAMARGO, O. A.; KINJO, T. Aplicação de três isotermas na adsorção de zinco em oxissolos, alfissolos e ultissolos. Revista Brasileira de Ciência do Solo, Campinas, v. 18, p. 15-20, 1994.

ELBACHÁ, A. T. Estudo da influência de alguns parâmetros no transporte de massa em solos argilosos. Rio de Janeiro: PUC, 1989. 178p. Dissertação Mestrado.

FERNANDES, L. A.; COIMBRA, A. M. Revisão estratigráfica da parte oriental da bacia Bauru (neocretáceo). Revista brasileira de Geociências, v. 30, n. 4, p.723-734, 2000.

FIGUEIREDO, O. A. R. Reações de superfosfato triplo e de cama de galinha poedeira com um Latossolo Bruno. Porto Alegre, 1985. 74p. Dissertação de mestrado - Universidade Federal de Porto Alegre.

FORD, R.G.; BERSTSCH, P. M.; FARLEY, K.J. Changes in transition and heavy metal partitioning during hydrous iron oxide aging. Environ. Sci. Technol, v. 31, p.2028-2033, 1997.

FUNDAÇÃO INSTITUTO AGRONÔMICO DO PARANÁ. IAPAR. Cartas climáticas básicas do Estado do Paraná. Londrina, IAPAR, 1978. 41 p. 


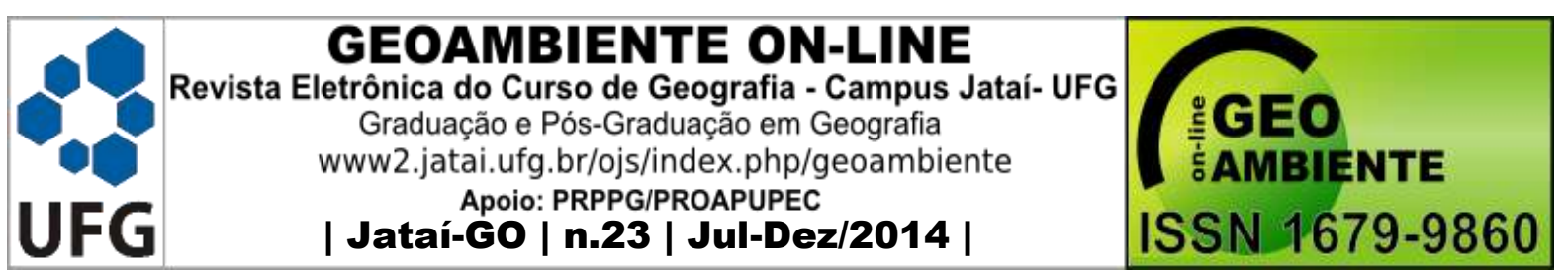

HAMILTON, M. A.; WESTERMANN, D. T.; JAMES, D. W. Factors affeting zinc uptake in cropping systems. Soil Science Society of America Journal, Madison, v. 57, p. 1310-1315, 1993.

LINDSAY, W. L.; FRAZIER, A. W.; STEPHENSON, H. F. Identification of reaction products from phosphate fertilizers in soils. Soil Science Society of America Proceedings, Madison, v. 26, p. 446-552, 1962.

MA, Q. Y.; LINDSAY, W. L. Measurements of free zinc+2 activity in uncontaminated and contaminated soils using chelation. Soil Science Society of America Journal, Madison, v. 57, p. 963-967, 1993.

MARTINEZ, C. E.; McBRIDE, M. B. Co-precipitates of $\mathrm{Cd}, \mathrm{Cu}, \mathrm{Pb}$ and $\mathrm{Zn}$ in iron oxides: Solid phase transformations and metal solubility after aging and thermal treatment. Clay Clay Min, v. 46, p. 537-545, 1998.

McBRIDE, M. B. Environmental chemistry of soils. New York, Oxford University Press, 1994, 406 p.MINERAIS DO PARANÁ S. A. MINEROPAR. Geoquímica de solo - Horizonte B. In: Levantamento Geoquímico Multielementar do Estado do Paraná. Curitiba, PR, Mineropar, 2005. v. 2. 407p.

OLIVEIRA, F. C.; MATTIAZZO, M. E. Mobilidade de metais pesados em um Latossolo Amarelo distrófico tratado com lodo de esgoto e cultivado com cana-de-açúcar. Scientia Agricola, v.58, p.807-812, 2001.

. Resolução CONAMA n 420, de 28 de dezembro de 2009. Dispõe sobre critérios e valores orientadores de qualidade do solo quanto à presença de substâncias químicas e estabelece diretrizes para o gerenciamento ambiental de áreas contaminadas por essas substâncias em decorrência de atividades antrópicas. Diário Oficial [da República Federativa do Brasil]; Brasília, 30 de Dez. 2009. Disponível em: <http://www.mma.gov.br/port/conama/legiabre.cfm?codlegi=620>. Acesso em 01 dez. 2014.

RUFINO, R.L.; BISCAIA, R.C.M.; MERTEN, G.H. Determinação do potencial erosivo da chuva do estado do Paraná, através de pluviometria: Terceira aproximação. Revista brasileira de Ciência do Solo, Campinas, v.17, p.439-444, 1993.

SAMPLE, E. C.; SOPER, R. J.; RACS, G. J. Reactions of phosphate fertilizers in soil. In: Khasawneh, F.E.; Sample, E.C., eds. The role of phosphorus in agriculture. Madison, cap. 11, p.253-310. 1980. 


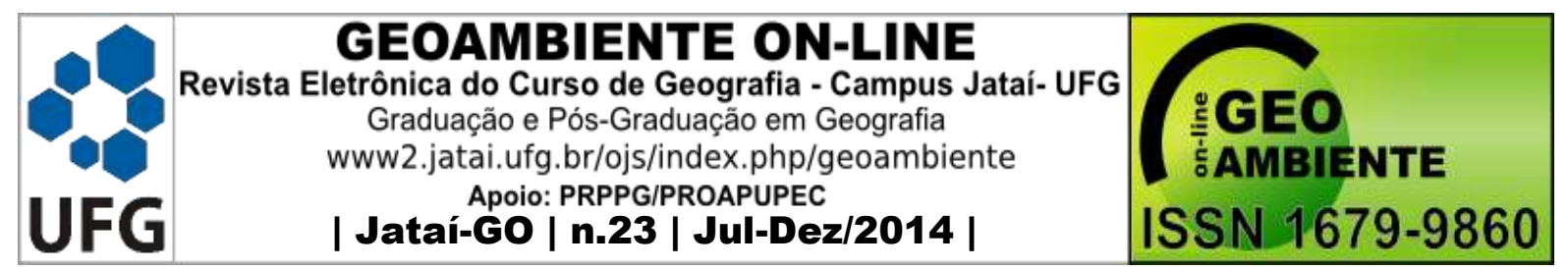

SANYAL, S. K.; DEDATTA, S. K. Chemistry of phosphorus transformations in soil. Adv.

Soil Sci. New York, v. 16, p2-120, 1991.

SANTOS, J. S. DOS; et al. Mobilidade de solutos em colunas de solo com água residuária doméstica e de suinocultura. Revista Brasileira de Engenharia Agrícola e Ambiental, v.14, p.1226-1233, 2010.

SODRÉ, F. F.; LENZI, E.; COSTA, A. C. S. Utilização de modelos físico-químicos de adsorção no estudo do comportamento do cobre em solos argilosos. Química Nova, v. 24, n. 03, p. 324-330, 2001.

STEVENSON, F. J. Humus chemistry. New York, John Wiley, 1982. 443p.

WERLE, R.; GARCIA, R. A.; ROSOLEM, C. A. Lixiviação de Potássio em função da textura e da disponibilidade do nutriente no solo. Revista Brasileira de Ciência do Solo. v. 32. n. 6. p. 2297 - 2305. 2008.

ZANÃO JÚNIOR, L. A.; LANA, R. M. Q.; GUIMARÃES, E. C. Variabilidade espacial do pH, teores de matéria orgânica e micronutrientes em profundidades de amostragem num Latossolo Vermelho sob semeadura direta. Ciência Rural, v. 37, n. 04, p. 1000-1007, 2007. 